\title{
Cultural Translation of Debate in Korean
}

\author{
Jee-won Hahn \\ Kyung Hee University
}

\begin{abstract}
Transformational processes of borrowed speech activities are addressed since the topic of debate. Debate is rooted in Western political discourse, and is now situated in Korean discourse. This study examines debate in order to understand the concept and rules of speaking which govern that activity. Considering the popularity of debate in Korean, particularly in educational domains, it seems only natural to see how Korean language/culture compares with and has modified a Western-oriented activity. The motivation of this current study is as a response to a prior lack of effort to look at language from a broader context. This study attempts to apply the ethnography of communication to debate proposed by Hymes $(1964 ; 1972 ; 1974)$. From the ethnographic approach to communication, speaking is inseparable from the context in which it takes place. The need to examine contextual factors is taken into consideration, and a set of components are identified to study language in use (i.e. setting, participants, keys, and norms). In this view, debate is analyzed as a cultural product. Findings reveal certain diverse features of 'Koreanized' debate. The language of Korean debate in expressing disagreement tends to be indirect. While agreement is directly expressed, disagreement is likely to be realized by means of disarmers and prefacing statements. The expression of oppositional opinion also becomes longer.
\end{abstract}


Keywords: debate, Korean speech acts, ethnography of communication, cultural borrowing, educational setting

\section{Introduction}

Debate has a political orientation in British schools and in the American parliamentary circuit, with two speakers per team and two teams per debate (Sather 1999). Debate as a Western-oriented activity has been adopted and is now utilized in Korean educational settings (Kim S. 2007; Kang et al. 2001). In particular, the practice of debate saw a dramatic cultivation in Asian countries wanting to obtain English proficiency by understanding the language through the cultural form of the borrowing languages. This study explores the cultural process of debate (Hymes 1972; 1974). It examines how the debating activity has been socialized among college students. And it also considers how it is interpreted, adopted and conducted. In understanding what debate is in Korean within the education setting, particular events accompanied by speech are understood from a broad perspective which includes contextual factors as well as linguistic ones.

\section{What is Debate?}

English debate comes from the Latin debattuere, which can be divided into two parts, de 'away, down' and battuere 'battle.' This etymology involves the meaning of 'battle' or 'game.' English debate translates into the Korean toron, while discussion translates into toui. Debate has had a long tradition dating back to the $1890 \mathrm{~s}$. Toron was borrowed from the Japanese translation of English during the colonial period (Kang et al. 2001; Shin 2005). This Korean translation is thus influenced by Japanese language and culture. In 
fact, the suitable Korean equivalent of debate is suggested as noncaeng 'argument', deriving from the original meaning of the English debate (Kang et al. 2001). Korean toron consists of two parts, to 'to divide a word', and ron 'to take turns in speaking'.

Toron and toui are used in daily life without much distinction, and are interchangeable. But in academic discourse, toron and toui are distinguished in terms of their purpose and structure. Toron mainly consists of two parties representing pros and cons for the given resolution, and its pedagogical purpose is to learn the skills of expressing one's opinions and persuading others. On the other hand, toui seeks to develop the skills of negotiation, in order to reach a solution through talking.

Within academia, debating has been thrust into the limelight due to its ability to increase knowledge and understanding. Curriculum and policies are influenced by social needs and changes. In particular, providing opportunities for students takes the central role in training college students. There has been a growing interest in class activities where linguistic competence is encouraged through debating skills. For example, college courses are labeled 'History and Debating,' 'Philosophy and Debating,' or 'Reading and Debating.' Debate is utilized as a means of acquiring knowledge about a subject.

Changes in curriculum can be accounted for in terms of internal and external factors. Internal factors derive from educational policies which encourage debate in class, as emphasis shifts from written language to spoken language (Kim P. 2007). Emphasis on competence in reading and writing has moved to an emphasis on speaking. As regards external factors, companies and corporations have begun to hire university graduates through oral interviews rather than through written examinations (personal communication with college students). The interviews require both speaking and presentation skills. Job market trends have influenced college policies. The ability to express ideas and verbalize them has become more 
valued. Self-expression and public speaking have become obligatory skills.

\section{Research on Korean Debate}

Interest in debate has increased as this activity becomes more common in educational domains. Studies on debating in the Korean setting can be summarized. These studies are, by and large, divided into several areas: education, communication, and linguistics. In the educational area, one important motivation for studying debate is to enhance debating competence at school. Interest in improving debating skills motivated many researchers to investigate debating competence and to explore methodological issues (Chung 2008; Kim S. 2007; Park 2004). These studies focused on the validity of debating as an educational tool. Debate in (mass) communication has been investigated according to specific genres, such as online, TV, or cyber-media (Lee D-W. 2008; Park 2002). In particular, as cyber-media increases, the effects of sources on debate are of concern. Historical works on Korean debate are found in Shin (2005), Lee (2006), and Chung (2006). These studies examined the influence of borrowing Western notions of debate on rhetoric, novels, and contemporary discourse.

In linguistics, debate has been analyzed from the theoretical framework of interactional sociolinguistics (Lee D-U. 2000; Lee DU. 2003; Song 1993). Researchers identified features characterizing debate in Korean. These studies analyzed the internal structure in terms of turn-taking and floor-taking. Lee D-U (2003) examined the use of linguistic means such as how they go about debating, and analyzed political speech within Goffman's frame theory for the use of questions and pronouns. Im (2001) examined the use of floortaking in TV debate.

Song (1993) identified strategies of Korean, in comparison with 
English, arguments. According to this finding, while English speakers express opposition directly, Koreans tend to express opposition indirectly, through the use of questions, repetition, and hedges.

The review of literature indicates research on debate has dramatically increased in different areas. However, linguistic approaches to debating are limited to the internal structure of the activity, while studies in the social sciences such as communication have become detailed and focus on debate in specific genres. This study takes an interdisciplinary position, bridging interest in language with that in context. The inspiration comes from Hymes' ethnography of communication (1974). This theory expands our knowledge from the internal to the external structure in order to understand the concept of debate.

\section{Theoretical background: Ethnography of Communication}

The ethnography of communication sees a system as a unit in which components are interrelated to constitute a structure. Dell Hymes' call for an ethnography of communication can be found in three main themes: (1) ethnographic methods, (2) a study of the communicative events that constitute the social life of a community, and (3) a model of the different components of the events. Speech behavior should be analyzed in its cultural and social context, in order to discover relevant features of variation. To quote Dell Hymes:

The starting point is the ethnographic analysis of the communicative habits of a community in their totality, determining what count as communicative events, and as their components, and conceiving no communicative behavior as independent of the set framed by some setting or implicit question. The communicative 
event thus is central. (Hymes 1964:13)

The task that Hymes set for himself was to connect the specifics of language use to the community within which such uses took place, were interpreted, and reproduced. The link within the community was established through the communicative event as a unit of analysis. The link within the community can be found in the statement that "the focus of the present approach is on communities organized as systems of communicative events" (1964:18).

Hymes (1974) argued that a speaker's linguistic ability is not limited to grammatical rules. He further proposed to include knowledge that enables the speaker to use language. This kind of knowledge was termed communicative competence. In order to analyze speech behavior, Hymes (1972) suggested a hierarchy of units (large-tosmall) called the speech situation (including speech genres), speech event, and speech act resulting from understanding of the social activities constituting the social life of a community. Hymes (1972: 56) described speech situations as "situations associated with (or marked by the absence of) speech". Speech situations are activities which may include speech events, but which also encompass the broader circumstances under which an event may take place. A speech event takes place within a speech situation, and is composed of one or more speech acts.

In the ethnography of speaking, speaking is viewed as a cultural system: setting, scene, participants, ends, act sequence, key, instrumentalities, norms, and genres. These components are included under the acronym S.P.E.A.K.I.N.G. For instance, setting refers to the time and place, i.e., the concrete physical circumstances in which speech takes place (e.g., home, office). Scene refers to the abstract psychological setting according to cultural definition (e.g., lectures, after dinner conversation, a cocktail party) which occur in a setting or describes an event which may include any number of speech activities (e.g., a visit to a friend's house, a chat over morning coffee). 
Duranti (1992) adopted a speech event approach in the description of Samoan. Instead of analyzing individual utterances isolated from conversation, he provided a grammatical description of the sentence or morphemes (e.g. case marking) as one part of the description of higher units, such as speech genres and speech events. If the object of linguistics is to explore such knowledge, then the speech act is the minimal unit to be examined. The notion of communicative competence played a role in turning a researcher's attention from grammatical to functional units. Blum-Kulka, House, and Kasper's (1989) understanding of speech acts is also related to Hymes's notion of speech acts. Under their analysis, a speech act enables researchers to investigate communicative competence.

This framework is used in addressing such issues as who is involved in the encounter and where it takes place (Agyekum 2008; Duff 1995; Fong 2000; Maduell 1994; Saville-Troike 1989; Tusda 1984). To understand communicative behavior, I focus attention on the situation in which the speech occurs, identifying the characteristics of individual speakers. I examine the content and form of the message, its manner or tone, and verbal exchanges. Moreover, interpretations and reactions of native speakers about Korean are useful tools for understanding verbal interactions.

\section{Data Collection}

Questionnaires are adopted to gather native speakers' interpretation of debate. A total of 13 questions are given, along with multiplechoice questions and one free written section. The choices are not arbitrarily selected; they are chosen to reflect common responses to based on the author's and other Koreans' interpretations. Thus, they may help respondents understand the point of the question and stimulate their thinking. Respondents can comprehend the intent of a question by looking at the given answers. Each question is designed 
to elicit information about the components of a speech event. Contextual information as well as linguistic features are collected through questionnaires.

The questionnaires are distributed to 42 students in two classes. Both classes are offered for intensive winter courses. One is for writing, and the other is for English. In the writing class in particular, debating is implicitly utilized as a means of organizing and developing the writing topics. For this reason, students of writing are able to respond to the survey based on their immediate experience.

\section{Korean Debate}

\subsection{Settings}

Due to the fact respondents are college students, the places in which they participate in debating activities are in the main schools and classes.

\subsection{Participants}

Debate is conducted in two essential ways: by groups or by individuals. The most preferred form of debate is with several groups, even though the original form of debate consists of two groups favoring the pros and cons. Due to the number of participants in a class activity, it is hard to work with a group of more than 5 or 6 members, and for this reason, a class is likely to be divided into several groups. The second common form consists of several groups led by a host speaker. This form may be familiar in class activities. Students recognize the role of the mediator. The mediator controls the flow and mood of the activity. When the members of a debate are few, each person puts forward one idea and the next person plays off of what the previous person has said. 


\subsection{Ends}

The goals and purposes of debating are surveyed with respect to two dimensions of debate: 'doing' debate and 'participating' in a debate. The first labeled as 'doing' debate refers to objective goals fallen on the event while the second, 'participating' debate refers to subjective goals for debaters. Students are trained to understand the goal of debates. Regardless of the purposes given for the event, participants may have their own practical reasons. Goals of the debating event are divided into two categories: self-oriented and other-oriented. The first focuses on benefits toward oneself while focusing on benefits deriving from the interaction. The otheroriented view is the most common. Respondents see the goal of debating in unders-tanding others. They see the goal of debate in the presence of others and a chance to share different opinions. The selforiented view takes into consideration one's improvement of verbal skills and competence of expression in public.

This distinction has to do with the choice of native words. The other-oriented goal involves talon 'other' or selo 'each other', referring to benefits coming from interaction. The self-oriented goals involves caki or casin, both meaning 'self', referring to benefits coming from one's own competence The third category is of neutral purposes, such as 'reaching a better solution.' They see the purpose of debating in neutral matters. Among them, the primary goal of debating is the other-oriented one. The secondary is selforiented. These two responses occupy the majority. The third group of respondents propose neutral-oriented views. The third can be related to other-oriented view since they propose the ultimate goal of exchanging ideas to seek better solutions.

For the goals of participants, more practical reasons appear such as expanding one's knowledge or furthering one's career. Participant goals include expanding knowledge of their majors, furthering their careers, and having fun. Among others, the most common response 
to the goal of debate is that participants want to expand their knowledge.

\subsection{Act Sequences}

Debate is carried out based on two main acts: agreeing or disagreeing with the prior speaker. In the context of debate, what is said is likely to be met with an agreement or with disagreement; these two acts can be major from an interactional point of view. Agreement is realized in forms such as using hedges, directly agreeing, and using non-verbal behavior. Among them, respondents consider good behavior to lie in making agreement by adding further comments, rather than by simply agreeing. In response to the question of how to agree, the common form of agreement is to use performative verbs, as in the speech act theory proposed by Searle (1976), such as chansenghata and tonguihata, both of which mean 'agree' as illustrated in (1):

(1) a. chansengha-p-nita

agree-AH-DEF

I agree.

b. ce-to tongueha-p-nita

I-also agree-AH-DEF

I also agree.

Without the use of the performative verbs, the speaker expresses the same idea. Example (2) illustrates this point:

(2) a. ce-to ku pupun-un kathun syangkak-ul ka-i-ko

I-also that part-TC same thought-AC

have-VS-and

iss-sup-nita

be-AH-DEF

I have the same opinion with that part. 


\section{b. ce-to kathun syangkak-ip-nita \\ I-also same thought-be-DEF \\ I have the same idea. \\ c. ce-to kulehkey syangkakha-p-nita \\ I-also like.that think-AH-DEF \\ I think like that.}

Remaining silent has a positive meaning. Some responses include remaining silent when they agree. Here we can see students prefer being silent instead of verbalizing their agreement. Nodding makes agreement clear. Non-verbal behavior has positive meaning, since it is used in making agreement, while it is not mentioned as a device for expressing disagreement. Nodding is a signal of reinforcing agreement.

Disagreement is realized in several ways such as using the 'but' phrase, using performative verbs, and proposing an alternative view. Among them, the use of the 'but' phrase is the most common. Any unpleasant or unwelcome message may need a 'disarmer' (Aijmer 1996). Aijmer discusses the use of apology words (like sorry) as a disarmer distinguished from its original function of expressing regret. A disarmer refers to words to soften the message before an unwelcome or face-threatening action.

The speaker avoids conflicts by using a disarmer in order to maintain social harmony between the participants. Efforts to minimize potential friction can be found. Students make partial acknowledgement, and then point out what is not disagreed. Relatively short phrases are used before saying something oppositional. These words acknowledge the truth of the other's opinion, like "understand" and "make sense."

Examples in (3) illustrate how opposition is expressed through the use of disarmers: 
(3) a. kuntey....

$$
\text { but.... }
$$

b. kuken kuleh-ciman

that like.that-but

That's right, but...

c. ihayha-ciman

understand-but

I understand, but....

Instead of short phrases or a single word, a disarmer can be long in the form of full sentences. The following sentences include more indirect forms of disagreement:

(4) a. kukes-to chungpunhi kanunghan iyaki-i-ciman cey-ka that-also fully possible story-be-but I-NM syangkakha-ki-ey-nun think-NOM-at-TC That really makes sense, but I don't think so.

b. cey-ka al-ki-lo-nun....ha-p-nita cey-ka calmos al-ko

I-NM know-NOM-with-TC...do-AH-DEF I-NM

wrong know-and iss-ess-na-yo

be-PST-VS-Q

I know ... is said. Did I get it wrong?

c. ... uy uykyen-un al-keyss-ciman cey syangkak-un

...POSS opinion-TC know-VS-but I thought-TC talu-p-nita

different-AH-DEF

I understand (someone)'s idea but I have a different one.

Many forms are indirect, including the use of disarmers. Another indirect form is the choice of words. In conveying bad news, respondents tend to use neutral words like talun 'different' to avoid judgmental words like thulin 'wrong.' 
(5) a. ce-nun ku pupun-ey tyayhyayse-nun talun

I-TC that part-for about-TC different

syangkak-ul kaci-ko iss-nun-tey-yo

thought-AC have-and be-VS-VS-POL

I have a different idea about that part.

b. ... uy cuchang-ul cal tul-ess-ciman ce-nun yakkan

...POSS claim-AC well hear-PST-but I-TC little

taluta-ko syangkakha-p-nita

different-and think-AH-DEF

I got what (someone) says, but it is a little bit different.

In some cases, disarmers may not be used; the speaker directly presents an idea without prefacing any comments or statements. Without expressing any disagreement or negative opinions, the speaker directly presents an idea. This is another way of expressing disagreement. Examples in (6) illustrate the speaker simply making a point without any prefacing comments.

Performative verbs include pantayhata, or in a negative form, tonguyha-ci anh-ta by using negation anh 'not'. Debaters may use a direct form of disagreement. Direct disagreement by using performative verbs such as pantaehapnita 'disagree' is limited to only a few instances ( 3 out of the total 42 responses).

(6) a. Cey syayngk-un....

I thought-TC

To my thinking, ....

b. ce-nun ....kkeyse malssumha-si-n uykyen-ey

I-TC ... NM speak-SH-NOM opinion-for

tonguyha-ci anh-sup-nita

agree-VS not-SH-DEF

I don't agree with (someone)'s opinion. 
Topics of debate are found in contemporary issues, majors, and business. Among them, contemporary issues are most preferred, since they provide various and current sources. Respondents get access to debate through contemporary issues rather than limited disciplines. Students learn the skills of debate through talking about diverse contemporary issues rather than restricting their interests.

The number of arguments over the issue at hand is not always restricted to two oppositions. Two or more positions are available, rather than simply focusing on two contradictory positions. Two parties consisting of pros and cons are not obligatory. Class debate is carried out close to a 'discussion' form rather than a 'debating' form. Students are encouraged to put forward their ideas and then tend to explore their ideas deeply. Debating as a class activity focuses on student participation, and allows them express their ideas with as little restriction as possible.

\subsection{Key}

For key, respondents select adjective form terms to describe debate. In the negative sense, debate is described as 'unmotivated' and 'attacking.' The most common negative term for debating is 'unmotivated'. Attacking refers to the tense atmosphere which arises when participants are emotional. An interesting response is to point this out as being 'foreign', since they feel it derives from other countries. They see a Korean style that is 'not genuine'. In the positive sense, debate is described as 'active' and 'serious.'

\subsection{Instrumentality}

Instrumentality refers to the media through which language is conveyed. The language mainly used in debates is the native language, Korean. A few respondents are familiar with the use of English. This face indicates the use of debate for motivating students in the language learning setting. 


\subsection{Norms}

Interruptions were pointed out by the respondents as being unacceptable. One problem for a participant would be in recognizing the appropriate time to express one's opinion. Many respondents feel that when they are interrupted, their opinions are being ignored. Norms suggested relate to turn-taking. Arguments may become more heated when the difficulty of sharing limited time increases, and participants and/or the topics become emotional.

The survey was intended to elicit descriptive rules that respondents are familiar with and commonly adopt, in order to obtain knowledge of the rules associated with debate. However, respondents answer with 'prescriptive' rules, which are expected or required behavior. Prescriptive rules of debate include those which should be avoided, and those that should be encouraged. Interruption and the use of unpleasant words should be avoided. Good listening is encouraged for better communication.

\section{Conclusion and Further Research}

This paper examined the characteristics of debate in Korean from a broad perspective consisting of a set of contextual factors. Korean debate is shown to undergo a process of transformation from the original form of debate. Social changes in debate can be found. Those who regard the act of debating as 'foreign' are limited to a few instances. Many students are used to debating, and do not raise serious objection.

However, some Korean students still see debate as oriented towards a foreign mentality. In describing the mood of debate, they answer in a negative sense that what they are doing is akin to a Western style. Debate doesn't feel like it is "ours", but is still the "other's" and "foreign". Participants do not consider themselves 
belonging to the members of the activity. Not belonging can be a critical obstacle to developing skills of language by weakening students' motivation. Cultural objection needs to be considered along with debating skills.

When disagreement is to be conveyed, indirect forms are mainly used. Using disarmers is typical. Instead of being direct, many forms are realized by prefacing. Softening the message is obvious. Here, we can find a key difference between Song (1993) and the current study. One-on-one interaction in a private setting can be different from one-on-one conversation involving an audience. While Song analyzes conversation in face-to-face interaction, the current study examines one-to-many interaction set in front of an audience. Use of disarmers to indirectly voice opposition is seen as a feature of formality, and is mostly used in a public setting. The goals of debate are classified into two categories: self-oriented and other-oriented. Interaction with others is considered the primary purpose of debating.

For further studies, speech behavior can be examined within politeness theory. According to Brown and Levinson (1987), disagreement is an act that threatens the addressee's positive face, since it may be received in a negative way by the hearer. Being indirect can be counted as a way of avoiding threat. Many college students are reluctant to express disagreement. Some students take an expression of disagreement as personal. Their emotions tend to be involved in the debating event. For this reason, it is pointed out being emotional needs to be prohibited. Emotional words can be taken as being personally directed. It is possible to examine how face-threat can vary according to cultures.

The present study mainly focused on Korean communication style and values. Further research might come from perception of debating. Reactions and interpretations of debating are the case. The effects on a speaker's feelings can be explored when someone else takes his/her turn inappropriately. This can be a source of miscommunication as well. 
Jee-Won Hahn 51

\section{References}

Agyekum, K. 2008. The Pragmatics of Akan Greetings. Discourse studies 10.4, 493-516.

Aijmer, K. 1996. Conversational Routines in English. London\& New York: Longman.

Blum-Kulka, S. et al. 1989. Cross-Cultural Pragmatics. Norwood, NJ: Ablex.

Brown, P. et al. 1987. Politeness: Some Universals in Language Usage. Cambridge: Cambridge University Press.

Chung, M. 2008. Toui toron swuep pangpep [Teaching Discussion and Debates]. Seoul: Kyoyukkwahaksa.

Chung, W. 2006. Yensel-kwa toron-ul thonghay pon kuntay kyemongki-uy swusahak [Rhetoric of Modern era Through Public Speech and Debates]. Kocen Munhakyenkwu 30, 409-446.

Duff, A. 1995. An Ethnography of Communication in Immersion Classrooms in Hungary. TESOL Quarterly 29.3, 505-537.

Duranti, A. 1992. Language in Context and Language as Context: the Samoan Respect Vocabulary. In A. Duranti \& C. Goodwin (eds.), Rethinking Context 77-99. Cam-bridge: Cambridge University Press.

Edmondson, J. 1981. On Saying You're Sorry. In F. Coulmas (ed.), Conversational Routines: Explorations in Standardized Communication Situations and Prepatterned Speech 273-288. The Hague\& NewYork: Mouton de Gruyter.

Farrow, S. 2006. Debating and Its Discontents. Language and Communication 26.2, 117-128.

Fong, M. 2000. 'Luck Talk' in Celebrating the Chinese New Year. Journal of Pragmatics 32, 219-237.

Howe, M. 2005. An Introduction to English Language Debate in Asia. Seoul: Ewha Womans University Press.

Hymes, D. 1964. Introduction: Toward Ethnographies of Communi- 
cation. In J. Gumperz \& D. Hymes (eds.), The Ethnography of Communication, 1-34. Washington D.C.: American Anthropologist.

Hymes, Dell. 1972. Models of the Interaction of Language and Social Life. In J. Gumperz \& D. Hymes (eds.), Directions in Sociolinguistics: The Ethnography of Communication 35-71. New York: Holt.

Hymes, Dell. 1974. Foundations in Sociolinguistics: An Ethnographic Approach. Philadelphia: University of Pennsylvania Press.

Im, K. 2001. TV torn-eyse palenkwen cwuko ppayaski-uy tamwha pwunsek [Taking the Floor in TV Debates]. Tamwhawa Inci 8.2, 181-203.

Kang, T, at et. 2001. Toron-uy pangpep [Ways of Debating]. Seoul: Kemyunikheyishenpwuksu.

Kim, P. 2007. Toron-uy pangpep [Ways of Debating]. Seoul: Kukhakcaryowon.

Kim, S. 2007. Touy nunglyenk sinchang-ul wihan touy kyoyuk-uy nayyong yenkwu [Content Analysis of Debating Education for Improving Eebating Competence]. Sahoyenehak 15.2, 31-55.

Kim, Y. 2007. Taking Turns in Class Discussions in English. Foreign Languages Education 14.4, 49-72.

Lee, C. 2006. Kyemongkwa seltuk-uy uysa sothong pangsik-uyroseuy toron-kwa toron sosel [Debating as a Communication of Persuasion and Debate Novels]. Hankwukmu-whakchongse 44, 219-243.

----. 2008. Toron-uy cenlyak [Strategies of Debating]. Seoul: Mwunhakkwa cisengsa.

Lee, D-U. 2000. Toron-uy sangho sahoy enehakcek yenku [An Interactional Sociolinguistic of Debating]. Doctoral dissertation. Seoul National University.

-----. 2003. Rethinking Goffman's Theory and an Interact-tional Sociolinguistic Analysis of Debate. Enehak 37, 197-221.

Lee, D-W. 2008. Hankwuk tayhaksayng-uy tibeyithu suthailey 
tayhan nayyongpwunsek [Content Analysis of Debating style Among Korea College Students]. Khemyunikheyishyenhakyenkwu 16.1, 79-101.

Maduell, M. 1994. On Stage Calls: An Ethnolinguistic Analysis of Spoken Language in Professional Flamenco Performance. Doctoral Dissertation. University of Hawaii at Manoa.

Park, C. 2004. Hankwuk-uy toron mwunhwa-wa toron kyoyuk [Debating Culture and Debating Education in Korean]. Kwukekyoyukhak Yonkwu 19, 289-318.

Park, Y. 2002. TV sayngpangsong toron taywha-eyseuy taywha cenkyak yenkwu [Analysis of Conversational Strategies in Live TV Debating]. Sahoyenehak 10.1, 169-196.

Saville-Troike, M. 1989. The Ethnography of Communication. New York: Blackwell.

Sather, Trevor. 1999. Pros and Cons: A Debater's Handbook (18th edition). London and New York: Routledge.

Searle, R. 1976. The Classification of Illocutionary Acts. Language in Society 5, 1-24.

Shin, J. 2005. Yensel toron-ilanun ceyto-uy yuip-kwa kamka-uy pyenhwa [Adoption of Public Speech and Debates and Their Influences]. Hankuk Kuntaymwunhakyenku 6.1, 9-41.

Song, K. 1993. An Interactional Sociolinguistic Analysis of Argument Strategies in Korean Conversational Discourse: Negotiating Disagreement and Conflict. Ph. D Dissertation. Georgetown University, Washington, D.C.

Tusda, A. 1984. Sales Talk in Japan and the United States: An Ethnographic Analysis of Contrastive Speech Events. Washington D.C.: Georgetown University Press. 


\section{Abbreviations}

$\begin{array}{ll}\text { AC } & \text { Accusative case particle } \\ \text { AH } & \text { Addressee honorifics } \\ \text { DEF } & \text { Deferential speech level } \\ \text { NOM } & \text { Nominalizer } \\ \text { NM } & \text { Nominal case particle } \\ \text { POSS } & \text { Possessive marker } \\ \text { SH } & \text { Subject honorifics } \\ \text { TC } & \text { Topic-contrast particle } \\ \text { VS } & \text { Verbal suffix }\end{array}$

\section{Questionnaire}

The survey aims to examine the concept of debates in Korean. You can choose one among the given choices. If there's no answer, please write your opinion in the last section. Information about you is sure to be kept confidential.

\section{Age:}

Gender:

1. Have you ever participated in a debate?
(1)Yes
(2) No

2. Where do you usually do debates? (Choose the most familiar one.)
(1) School
(2) Workplace
(3) Clubs
(4) Others:

3. How many people usually participate in debates?
(1) Individuals
(2) Two groups
(3) Several groups
(4) Several groups and one mediator
(5) Others: 
4. How would you define debating? What kind of act is debating for?

5. Why do you participate in debates?

(1) To gain more knowledge about your major

(2) To help your career

(3) Others

6. What would you say when you disagree with the speaker?

7. What would you say when you agree?

8. Where do you usually find the topic of debating?
(1) Business
(2) Majors
(3) Current issues
(4) Others:

9. How would you describe the mood of debating in a positive way?
(1) Enthusiastic
(2) Serious
(3) Active
(4) Others:

10. How would you describe the mood of debating in a negative way?
(1) Quiet
(2) Foreign
(3) Unmotivated
(4) Others:

11. What language do you usually speak when debating?
(1) English
(2) Korean
(3) Japanese
(4) Others:

12. What is the ordinary form of doing debates?
(1) Talking about one topic based two groups, that is to say, pros and cons
(2) Talking about one topic by exchanging ideas
(3) Question and answer style
(4) Others:

13. What kinds of rules are common in a debate? 